\title{
BMJ Open Contexts of sedentary time and physical activity among ageing workers and recent retirees: cross-sectional GPS and accelerometer study
}

\author{
Sanna Pasanen (D) , ${ }^{1,2}$ Jaana I Halonen (D) , ${ }^{3}$ Anna Pulakka, ${ }^{4}$ Yan Kestens, ${ }^{5,6}$ \\ Benoit Thierry, ${ }^{6}$ Ruben Brondeel (D) , J Jaana Pentti, ${ }^{1,8}$ Jussi Vahtera (D) , ${ }^{1,2}$ \\ Tuija Leskinen (D) , ${ }^{1,2}$ Sari Stenholm (i) 1,2
}

To cite: Pasanen S, Halonen Jl, Pulakka A, et al. Contexts of sedentary time and physical activity among ageing workers and recent retirees: cross-sectional GPS and accelerometer study. BMJ Open 2021;11:e042600. doi:10.1136/ bmjopen-2020-042600

- Prepublication history and additional supplemental material for this paper are available online. To view these files, please visit the journal online (http://dx.doi.org/10.1136/ bmjopen-2020-042600).

Received 14 July 2020

Revised 09 April 2021

Accepted 28 April 2021
Check for updates

(C) Author(s) (or their employer(s)) 2021. Re-use permitted under CC BY-NC. No commercial re-use. See rights and permissions. Published by BMJ.

For numbered affiliations see end of article.

Correspondence to

Sanna Pasanen;

sanna.pasanen@utu.fi

\section{ABSTRACT}

Objectives We examined sedentary time and physical activity in different contexts among ageing workers, between their workdays and days off, and recent retirees, between their weekdays and weekend days.

Design Cross-sectional study.

Setting Finnish Retirement and Aging study and

Enhancing physical activity and healthy ageing among recent retirees-Randomised controlled in-home physical activity trial.

Participants 137 workers (544 measurement days) and 53 retirees (323 days), who provided data for at least 1 workday/weekday and 1 day off/weekend day.

Primary and secondary outcome measures Physical activity behaviour was measured with a combined Global Positioning System and accelerometer device (SenseDoc V.2.0), providing information on sedentary time, light physical activity and moderate-to-vigorous physical activity (MVPA) by locations (home or non-home) and trips (active travel, ie, speed $<20 \mathrm{~km} /$ hour and passive travel, ie, speed $\geq 20 \mathrm{~km} /$ hour).

Results Workers accumulated more sedentary time and physical activity at non-home locations than at home on workdays, while the opposite was confirmed for days off $(p<0.01)$. Workers accrued more MVPA on days off than on workdays (34 vs $28 \mathrm{~min}, p<0.05$ ), of which 9 min on workdays and 14 min on days off was accrued during active travel. Retirees' physical activity behaviour did not differ between weekdays and weekend days ( $p>0.05)$. Regardless of the day, retirees accumulated 33 min of daily MVPA, of which 14 min was accrued during active travel. Conclusions Workers accumulated more MVPA on days off than on workdays, and their activity behaviour varied between workdays and days off at different locations. Our results showed that a large proportion of the MVPA was accumulated during travel at slower speeds, which suggests that active travel could be a feasible way to increase MVPA among older adults.

Trial registration number NCT03320746.

\section{INTRODUCTION}

With advancing age, physical activity is essential for maintaining health and physical functioning. ${ }^{1}$ Physical activity can be accrued from
Strengths and limitations of this study

- Physical activity behaviour was measured with a device including Global Positioning System and accelerometer capabilities; this allowed us to measure simultaneously both the intensity and the contexts of physical activity.

- We were able to separate workdays and days off based on the diary filled in by the workers, rather than estimating workdays based on the day of the week, as has commonly been done in prior studies.

- Our study population consisted of older adults and therefore the results may not be generalisable to younger age groups. In addition, the percentage of men was small among both workers and retirees, limiting the generalisability of the findings to men.

- Our attempt to indicate active travel using the dichotomy of trips with a speed of less or more than $20 \mathrm{~km} /$ hour is somewhat rudimentary, as trips with a speed of less than $20 \mathrm{~km} /$ hour may also include slow driving, for example, in traffic congestion.

- Cross-sectional study design does not allow causal inference.

different domains including work, leisure and travel. Earlier studies have reported that physical activity differs between workdays and days off in adult populations. ${ }^{23}$ Furthermore, the daily physical activity on workdays has been found to vary by commuting mode ${ }^{45}$ and occupation. ${ }^{36}$ It has been reported that after retirement, physical activity decreases particularly when retiring from manual occupations $^{57}$ and that sedentary time increases after retirement especially among women and remains at a high level among men. ${ }^{8}$ However, few studies have been conducted with device-based measurements to examine the contexts of sedentary time ${ }^{9}$ and physical activity ${ }^{10}$ among older adults. Recent developments in wearable sensors, such as combining 
Global Positioning System (GPS) devices with accelerometers, have made this possible.

Previous studies have shown that the physical activity of older adults often takes place on roads, ${ }^{11}$ in areas where the density of shops and restaurants is high, ${ }^{12}$ and during travel. ${ }^{13}$ Prior findings suggest that most of the adults' moderate-to-vigorous physical activity (MVPA) was accumulated at home and in the workplace, but the highest MVPA ratios in relation to total time spent at a location were obtained at sport facilities and during travel. ${ }^{14}$

To the best of our knowledge, no previous study has focused on different levels of activity intensity, including sedentary time, of ageing workers' and recent retirees while also using information about the type of day and the context of the activity behaviour. Workers of over 55 years of age have been defined as ageing workers. ${ }^{15}$

Therefore, the aim of this study was to examine the differences in sedentary time, light physical activity and MVPA, among ageing workers and recent retirees in different contexts using accelerometer and GPS measurements. To increase the precision in our estimates, the accumulated minutes of activity (sedentary time, light physical activity and MVPA) were calculated separately by location (home, non-home locations) and during trips (ie, relocation from one place to another or making a round trip, dichotomised as active travel: speed $<20 \mathrm{~km} /$ hour or passive travel: speed $\geq 20 \mathrm{~km} /$ hour), and by the type of day (workdays and days off for those still at work, and on weekdays and weekend days for retirees).

\section{MATERIALS \& METHODS Study population}

The study population consisted of participants from the Finnish Retirement and Aging study (FIREA) and the Enhancing physical activity and healthy ageing among recent retirees-Randomised controlled in-home physical activity trial (REACT). In this study, we used baseline data from both these studies.

The FIREA study is an ongoing longitudinal cohort study of older public sector workers in Finland, established in 2013. The detailed description of the FIREA study design has been reported elsewhere. ${ }^{16}$ Briefly, participants were first contacted using a questionnaire 18 months prior to their estimated retirement date, which was obtained from the Pension Insurance Institute for the Municipal Sector in Finland (Keva). In Finland, the Public Sector Pensions Act regulates the retirement ages of the public sector employees. From 2005 onwards, public sector employees were permitted to retire, at the earliest, after reaching the age of 63 years and, at the latest, after reaching 68 years of age. Information on the estimated retirement date was used in the formation of the FIREA study population as well as in scheduling the data collection. None of the participants from the FIREA study included in the current study had reached their estimated retirement date and were all still working. In the REACT study, all participants had already retired. After responding to the general questionnaire, the Finnishspeaking participants with an estimated retirement date between 2017 and 2019, who were still working and who lived in Southwest Finland, were invited to participate in a clinical substudy $(\mathrm{n}=773)$. Of these, $290(38 \%)$ participated in the clinical substudy between September 2015 and May 2018. The GPS measurements were included in the protocol in March 2016.

The REACT study is a randomised controlled trial, which examines the effectiveness of a 12-month technologybased intervention on sedentary time and physical activity among newly retired participants. The REACT study comprised 231 Finnish public sector employees who retired between January 2017 and December 2018. The baseline measurements for the REACT study were conducted on average 1 year and 2 months after retirement (range: 0 months to 32 months, SD 6.4 months).

A GPS and accelerometer device was proposed for 213 FIREA participants and 61 REACT participants. Four FIREA participants did not want to wear the device; one reported reason was that the device was considered too large and uncomfortable. Three FIREA and one REACT participant encountered technical problems with the GPS device and thus did not provide any GPS and accelerometer data. Consequently, there were 206 FIREA participants and 60 REACT participants who successfully used the device.

In the study, we included those measurement days on which the participants wore the GPS and accelerometer device for $600 \mathrm{~min}$ or more, which is commonly used as the required cut-off for a valid day. ${ }^{10}{ }^{17}$ Wear time was detected using Choi's method, which flags as non-wear time any measure within a $90 \mathrm{~min}$ time window of consecutive zero counts, allowing a 2-min interval of non-zero counts with the up/downstream $30 \mathrm{~min}$ consecutive zero counts window. ${ }^{18}{ }^{19}$ Furthermore, we restricted the sample to those FIREA participants who provided data for at least one workday and 1 day off, and the REACT participants to those with valid data for at least 1 weekday and 1 weekend day. The final analytical sample included 137 participants (544 days) for the FIREA study and 53 participants (323 days) for the REACT (flow chart provided as online supplemental figure 1). The measurement for the participants who met the selection criteria was completed during spring (38\%), summer (15\%), autumn (23\%) and winter (25\%) for the FIREA participants; while in the REACT study the measurements were completed during spring (23\%), autumn (47\%) and winter (30\%).

\section{Patient and public involvement statement}

No patients or the members of the public were involved in the development of the research question or the design of this study. The volunteer study cohort participants were involved in the conduct of the study.

\section{GPS and accelerometer measurements}

We used a waist-worn SenseDoc V.2.0 device (Mobysens Technologies, Canada) for measuring physical activity 
behaviour and its contexts in both studies. A study nurse supplied and gave instructions on the use of the device to the participants during a clinical examination visit. The FIREA participants were asked to wear the device for a minimum of 2 workdays and 2 days off, and the REACT participants were asked to wear the device during all waking hours except when bathing or swimming on seven consecutive days. Participants, in both studies, were asked to keep a diary where they provided information about their bedtimes, and in addition the FIREA participants were asked to record their workdays and days off. After the measurement period, the participants returned the devices and the diaries by mail.

The embedded sensors of the SenseDoc V.2.0 device include a high-sensitivity GPS receiver and a tri-axial accelerometer. The detailed description of the features of the device has been reported elsewhere. ${ }^{13}$ In both studies, the devices were initialised to record GPS data at every 1 $\mathrm{s}$ and accelerometer data at an $80 \mathrm{~Hz}$ sampling rate. The raw GPS and accelerometer data were extracted from SenseDoc V.2.0 with SenseAnalytics (V.1.9 and V.1.10) before being aggregated into counts at 1-min epochs. The software used to process the raw GPS and accelerometer data were Python (V.3.6.6), R (V.3.5.3), ArcGIS (V.10.3.1) and Postgresql (V.11.1) with a PostGIS extension (V.2.5.1 r17027).

\section{Identification of locations and trips}

We used an algorithm developed by Thierry et al. ${ }^{20}{ }^{21}$ to identify locations visited and trips made from raw GPS data. A location was defined as a place where the participant stayed for a longer time or a place where the participant made frequent shorter visits, regardless of his or her physical activity levels. A trip was defined as the travel between two locations or making a round trip. The trip could include different modes of travel, and during the same trip various levels of physical activity may have occurred. To identify the home location, we compared the coordinates of the identified GPS locations to the participants' registered home address coordinates. The location, which was the nearest to and within $100 \mathrm{~m}$ of the participant's registered home address was marked as the participant's home. For those participants who did not have a registered address $(n=6)$ or the distance between the home address and the nearest identified location was more than $100 \mathrm{~m}(\mathrm{n}=11)$, the home was determined to be the location where the participant spent most of his/her time. Of the home locations defined by the coordinates, 94\% were also the locations where most time was spent during the measurement. All other identified locations except the home were consequently defined as non-home locations. For each trip, the travelling speed was calculated based on the trip length and trip duration $(\mathrm{km} /$ hour). The trips were divided according to average travelling speed into $<20 \mathrm{~km} /$ hour trips and $\geq 20 \mathrm{~km} /$ hour trips, suggesting active and passive travel, respectively. In an urban environment and among an ageing population cycling ${ }^{22}{ }^{23}$ is also likely to be included in the $<20 \mathrm{~km} /$ hour category. The software used to identify the locations and trips were ArcGIS (V.10.3.1) and Postgresql (V.11.1) with a PostGIS extension (V.2.5.1 r17027).

\section{Measurement of sedentary time and physical activity}

Raw accelerometer data were converted to ActiGraph equivalent activity counts using the Brønd et al algorithm $^{24}$ (for details, see the 'activityCounts' package in $\mathrm{R}^{25}$ ). Counts per second were then aggregated into counts per minute to apply commonly used thresholds for activity intensity: sedentary behaviour ( $\leq 100$ counts/ $\mathrm{min}$ ), light physical activity (>100 and $\leq 2020$ counts $/ \mathrm{min}$ ) and MVPA ( $>2020$ counts $/ \mathrm{min}) .{ }^{26}$ Time spent on each activity intensity level was aggregated for each location and trip identified on a day-to-day basis. To separate the days, we used the recorded bedtime from the diaries.

\section{Covariates}

Age, gender, occupational status, mobility limitations, body mass index (BMI) and neighbourhood disadvantage were considered as covariates because of their known association with sedentary behaviour ${ }^{27}$ and physical activity. ${ }^{38-30}$ In addition, we took the device wear time and measurement season (spring, summer, autumn and winter) into account in the analyses. Information regarding age, gender and occupational status were obtained from the register of the Pension Insurance Institute for the Municipal Sector in Finland (Keva). Occupational status was categorised into two groups based on the International Classification of Occupations (ISCO $)^{31}$ : non-manual (ISCO classes 1-4, eg, physicians, teachers, registered nurses and secretaries) and manual (ISCOclasses 5-9, eg, practical nurses, cooks, maintenance workers and cleaners). Information regarding mobility limitation was based on the validated RAND-36 Health Survey (identical with the Short Form SF-36) ${ }^{32-34}$ Mobility limitation was defined as having difficulty in walking 2 $\mathrm{km}$, and it was categorised into no limitations (no) and limitations (somewhat and markedly). Body weight and height were measured during the clinical examination at baseline, and BMI was calculated (as weight in $\mathrm{kg} / \mathrm{height}$ in $\mathrm{m}^{2}$ ). For neighbourhood disadvantage, we calculated a standardised index based on the national mean of household incomes (inversely coded), the proportion of those with a low education and the percentage of unemployment in the home neighbourhood $(250 \times 250 \mathrm{~m}$ map grid cell); this information was obtained from the population registers provided by Statistics Finland. The specifics of this variable have been described elsewhere. ${ }^{35} 36$

\section{Statistical methods}

Characteristics of the participants were described as mean values with $\mathrm{SD}$ for continuous variables, and as frequencies and percentages for categorical variables. Linear regression analysis with generalised estimating equations (GEE) were used to compare mean daily sedentary time, light physical activity and MVPA between workers and retirees in total and at different locations and during trips. The 
GEE models controlled for the intra-individual correlation between repeated measurement days. The models were first adjusted for age, gender and device wear time, and then further for season, occupational status, mobility limitations, BMI and neighbourhood disadvantage.

As sensitivity analyses, we tested the influence of one data selection decision: we used four different speed thresholds to dichotomise the trips in addition to $20 \mathrm{~km} /$ hour used in the main analyses: $16 \mathrm{~km} /$ hour, $18 \mathrm{~km} /$ hour, $22 \mathrm{~km} /$ hour and $24 \mathrm{~km} /$ hour.

Statistical analyses were performed using SAS statistical software, V.9.4 (SAS Institute).

\section{RESULTS}

The majority of the participants in the FIREA and REACT studies were women, $87 \%$ and $91 \%$, respectively. The mean age was 62.4years (range 60-64, SD 1.0) for workers (FIREA) and 64.8 (range 62-67, SD 1.1) for retirees (REACT). Onethird of the participants were manual workers and about $10 \%$ had mobility limitation in both study populations. The mean BMI was higher among retirees (28.3, SD $\left.4.6 \mathrm{~kg} / \mathrm{m}^{2}\right)$ than among workers $\left(26.0, \mathrm{SD} 4.5 \mathrm{~kg} / \mathrm{m}^{2}\right)$, while the mean standardised neighbourhood disadvantage was rather similar between workers $(-0.1, \mathrm{SD} 0.7)$ and retirees $(0.1$, SD 1.0). No notable differences in the above-mentioned characteristics were observed between eligible sample and study population. Workers provided valid measurement data for an average of 4.0 days (SD 1.2) and retirees for 6.1 days (SD 1.2) (table 1 ).

Table 1 Characteristics of the eligible sample and study population

\begin{tabular}{|c|c|c|c|c|}
\hline \multirow[b]{2}{*}{ Variable } & \multicolumn{2}{|l|}{ Eligible sample } & \multicolumn{2}{|l|}{ Study population } \\
\hline & $\begin{array}{l}\text { Workers (FIREA) } \\
(n=213)\end{array}$ & $\begin{array}{l}\text { Retirees (REACT) } \\
(n=61)\end{array}$ & $\begin{array}{l}\text { Workers (FIREA) } \\
(n=137)\end{array}$ & Retirees (REACT) $(n=53)$ \\
\hline \multicolumn{5}{|l|}{ Gender n (\%) } \\
\hline Male & $31(14.6)$ & $6(9.8)$ & $18(13.1)$ & $5(9.4)$ \\
\hline Female & $182(85.5)$ & 55 (90.2) & $119(86.9)$ & $48(90.6)$ \\
\hline \multicolumn{5}{|l|}{ Occupational category n (\%) } \\
\hline Non-manual & $142(66.7)$ & $41(67.2)$ & $92(67.2)$ & $37(69.8)$ \\
\hline Manual & 71 (33.3) & $20(32.8)$ & 45 (32.9) & $16(30.2)$ \\
\hline \multicolumn{5}{|l|}{ Mobility limitation n (\%) } \\
\hline No limitations & $191(90.1)$ & $56(91.8)$ & $125(91.2)$ & $48(90.6)$ \\
\hline Limitations & $21(9.9)$ & $5(8.2)$ & $12(8.8)$ & $5(9.4)$ \\
\hline \multicolumn{5}{|l|}{ Age } \\
\hline Mean (SD) & $62.4(1.0)$ & $64.8(1.1)$ & $62.4(1.0)$ & $64.8(1.1)$ \\
\hline \multicolumn{5}{|l|}{ BMI } \\
\hline Mean (SD) & $26.4(4.8)$ & $28.0(4.6)$ & $26.0(4.5)$ & $28.3(4.6)$ \\
\hline \multicolumn{5}{|l|}{$\begin{array}{l}\text { Neighbourhood } \\
\text { disadvantage }\end{array}$} \\
\hline Mean (SD) & $-0.1(0.7)$ & $0.1(0.9)$ & $-0.1(0.7)$ & $0.1(1.0)$ \\
\hline \multicolumn{5}{|l|}{ Measurement season $\mathrm{n}(\%)$} \\
\hline Spring & & & $52(38.0)$ & $12(22.6)$ \\
\hline Summer & & & $20(14.6)$ & $0(0.0)$ \\
\hline Autumn & & & $31(22.6)$ & $25(47.2)$ \\
\hline Winter & & & $34(24.8)$ & $16(30.2)$ \\
\hline \multicolumn{5}{|l|}{$\begin{array}{l}\text { Valid data ( } \geq 600 \text { min wear } \\
\text { time/day) }\end{array}$} \\
\hline All days mean (SD) & & & $4.0(1.2)$ & $6.1(1.2)$ \\
\hline $\begin{array}{l}\text { Workdays/weekdays } \\
\text { mean (SD) }\end{array}$ & & & $2.1(0.9)$ & $4.3(1.0)$ \\
\hline $\begin{array}{l}\text { Days off/weekend days } \\
\text { mean (SD) }\end{array}$ & & & $1.9(0.7)$ & $1.8(0.5)$ \\
\hline
\end{tabular}

${ }^{\star}$ Frequency missing: eligible sample 47, study population 27.

FIREA, Finnish Retirement and Aging study; REACT, Enhancing physical activity and healthy aging among recent retirees - Randomized controlled in-home physical activity trial. 


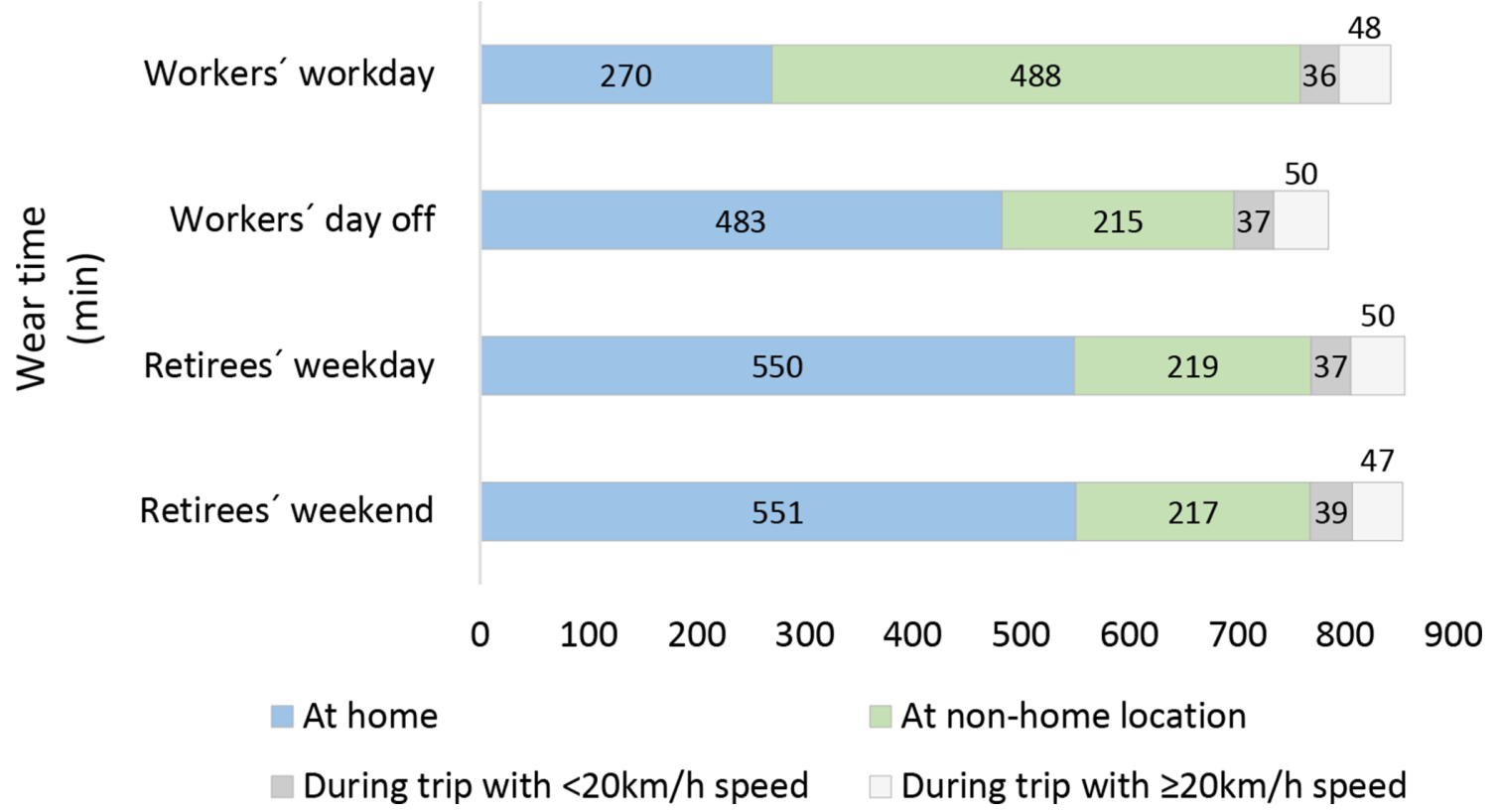

Figure 1 Distribution of daily device wear time (min) between home, non-home locations and during trips among workers and retirees.

Figure 1 illustrates the mean (unadjusted) wear time on workdays and days off for workers, as well as on weekdays and weekend days for retirees by locations and trips. Among the workers, the majority of wear time was accumulated at non-home locations on workdays $(488 \mathrm{~min}$ ) and at home during days off ( $483 \mathrm{~min})$. Among retirees, the majority of their wear time was accumulated at home both on weekdays $(550 \mathrm{~min})$ and on weekend days (551 min). Wear time spent during trips did not vary by the type of day among workers or retirees.

Figure 2 (unadjusted) and table 2 (adjusted for all covariates) present mean daily sedentary time, light physical activity and MVPA for workers and retirees by the type of day in total and at different locations and during trips. The mean daily sedentary time and light physical activity in total did not markedly differ between days and working status, but workers accumulated 6 min more MVPA on their days off than on workdays ( 34 vs $28 \mathrm{~min}$, respectively, $(\mathrm{p}=0.017))$.

Next, we examined in more detail the activity behaviour across different locations and trips (table 2). Workers accumulated markedly more of their sedentary time (330 vs $167 \mathrm{~min}(\mathrm{p}<0.001)$ ), light physical activity (162 vs $85 \min (\mathrm{p}<0.001))$ and MVPA (12 vs $8 \mathrm{~min}(\mathrm{p}=0.0032))$ at non-home locations on workdays compared with days off. Conversely, more of the workers' sedentary time (321 vs $163 \mathrm{~min}(\mathrm{p}<0.001)$ ), light physical activity (148 vs $74 \min (\mathrm{p}<0.001))$ and MVPA $(11$ vs $6 \min (\mathrm{p}<0.001))$ was accumulated at home on days off versus workdays. Of the workers' MVPA, more was accumulated during active travel (trip speed $<20 \mathrm{~km} /$ hour) than passive travel (trip speed $\geq 20 \mathrm{~km} /$ hour) (workdays 9 vs $2 \mathrm{~min}$, days off 14 vs $1 \mathrm{~min}$ ), respectively. Active travel accumulated a relatively large share of the mean daily total MVPA (workdays $28 \mathrm{~min}$, days off $34 \mathrm{~min}$ ). There were more MVPA minutes accrued during active travel on workers' days off than on workdays ( $\mathrm{p}=0.0089$ ).

Retirees' levels of physical activity (sedentary time, light physical activity and MVPA) did not differ $(p>0.05)$ either by location or by travel between weekdays and weekend days. Similar to workers, a larger proportion of the retirees' MVPA was acquired during active than passive travel, on both weekdays (14 vs $2 \mathrm{~min}$ ) and weekend days (14 vs $1 \mathrm{~min}$ ). Active travel accumulated a considerable proportion of the mean daily total MVPA (weekdays $34 \mathrm{~min}$, weekend days $33 \mathrm{~min}$ ).

As an average for all days (adjusted for all covariates), retirees accumulated less sedentary time ( 511 vs $545 \mathrm{~min}$, respectively $(\mathrm{p}=0.0364)$ ), more light physical activity (288 vs $256 \mathrm{~min}(\mathrm{p}=0.0399)$ and the same amount of MVPA (33 vs 31 min ( $>0.05)$ than workers.

Results for the analyses adjusted only for age, gender and wear time are presented in online supplemental table 1 , and the estimates were rather similar to those in the more adjusted main analysis. Using different trip speeds to discern active travel did not markedly change the results (online supplemental table 2).

\section{DISCUSSION}

This study used a device with GPS and accelerometer capabilities to examine physical activity behaviour at different locations and during trips among ageing workers and recent retirees. Workers' activity behaviour varied between workdays and days off at different locations; they accumulated more sedentary time, light physical activity and MVPA at non-home locations than at home on workdays, and conversely, more sedentary time and physical activity at home than at non-home locations on their days off. Retirees' activity behaviour was similar between 

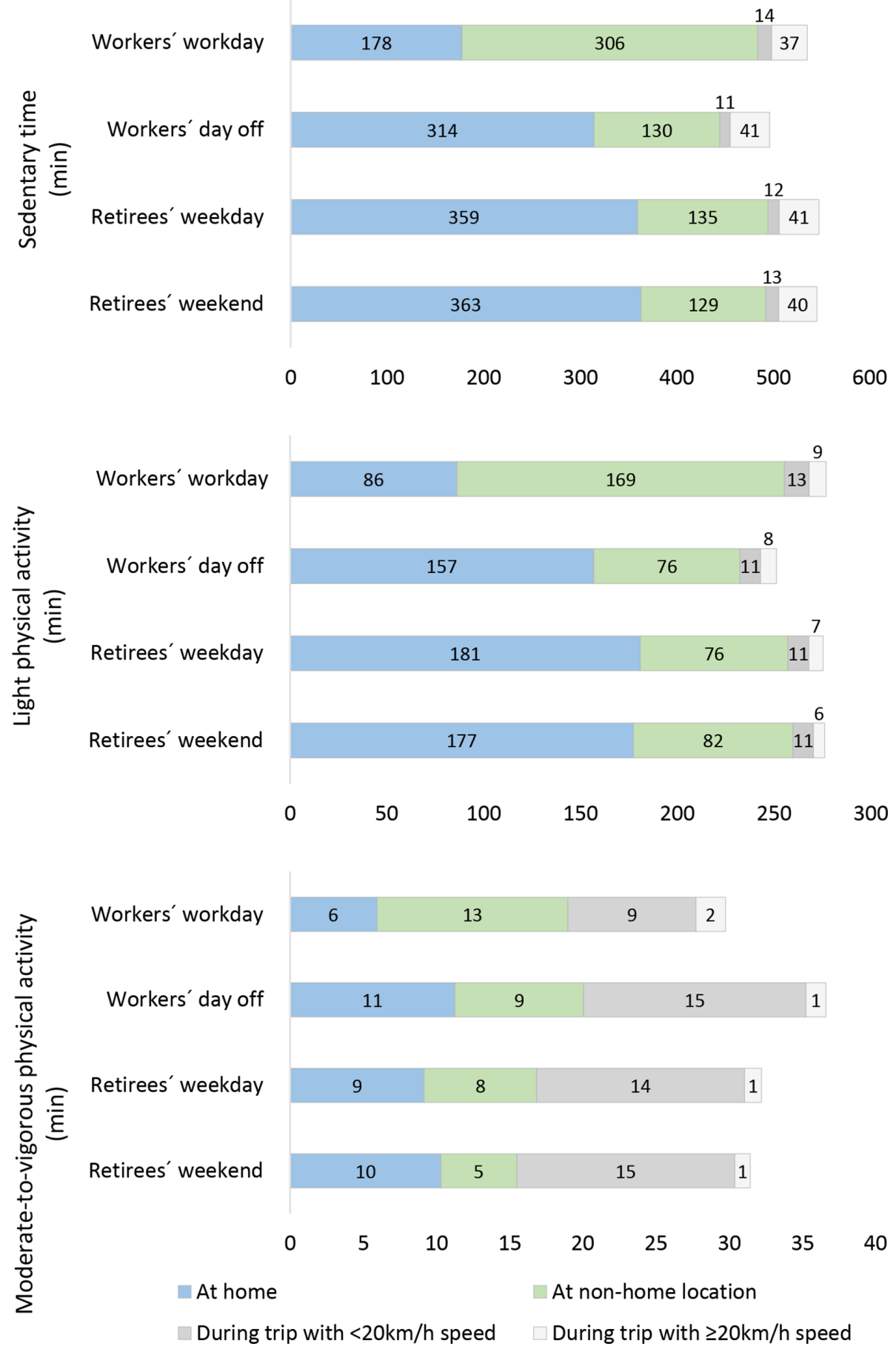

Figure 2 Sedentary time, light physical activity and moderate-to-vigorous physical activity (min) on workdays and days off for workers, and weekdays and weekend days for retirees at home, non-home locations and during trips.

weekdays and weekend days. With regard to the trips, a large proportion of mean daily total MVPA was acquired from active travel (trip speed $<20 \mathrm{~km} /$ hour) among both workers and retirees.

Workers accumulated more MVPA on days off than on workdays, and the workers' MVPA during their days off reached the same level as retirees' MVPA on any day. This finding is in line with the study of Mutikainen $e t a l,{ }^{2}$ in which they observed that MVPA and vigorous physical activity, as estimated by R-R interval data, were higher during days off than on working days among Finnish employees; this was also confirmed in a subsample of 51-65 years old. However, it must be pointed out that the study population of Mutikainen $e t a l^{2}$ was younger than our study population, thus the results are not directly comparable. Using data from the FIREA study (mean age 62.4 years), Pulakka $e t a l^{3}$ compared leisure-time physical activity patterns based on a wrist-worn accelerometer, and observed that especially female non-manual workers were more active on days off than on working days, while both female and male manual workers were more active on working days than on days off. Moreover, recent follow-up 


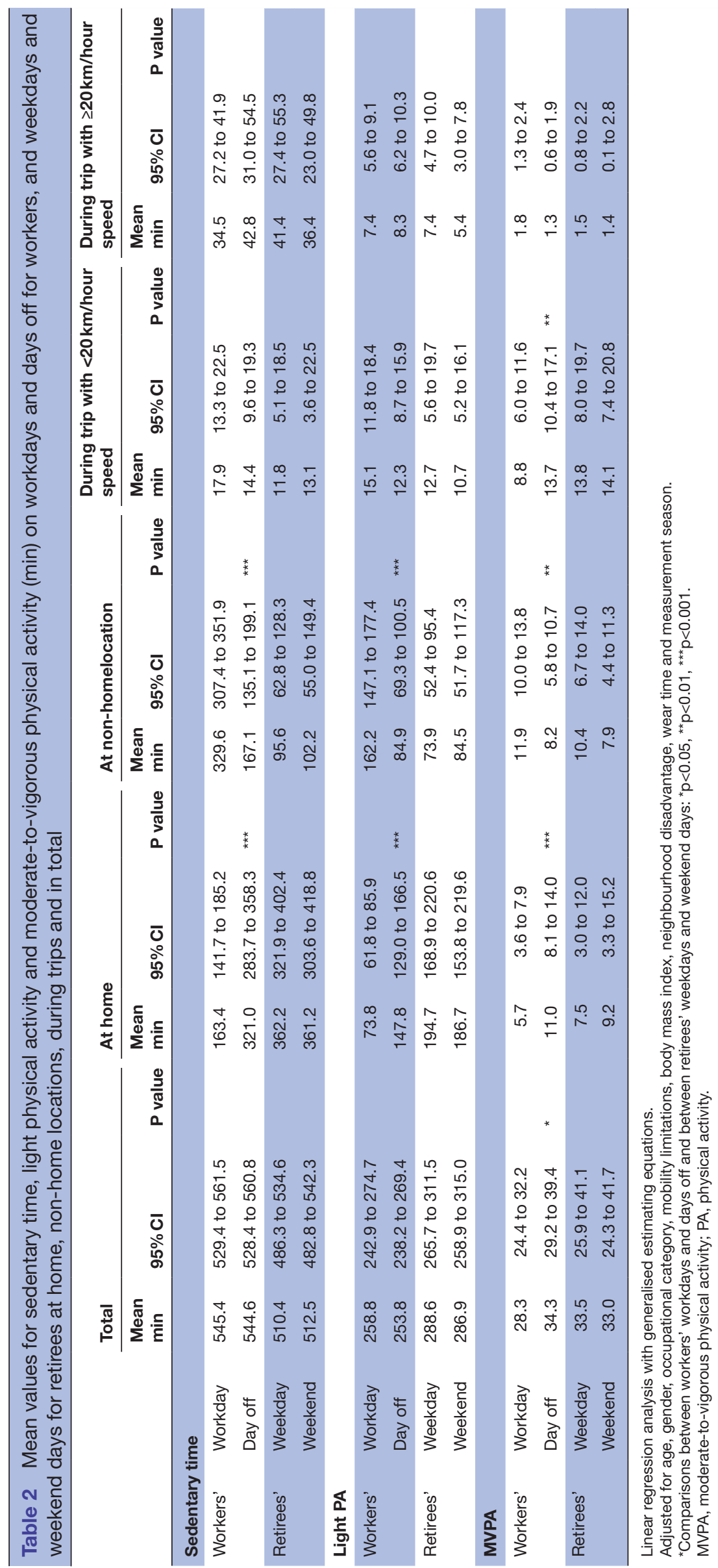


studies have reported increased sedentary time ${ }^{8}$ and decreased physical activity ${ }^{5}$ among women retiring from manual occupations. Among men, there seems to be no retirement related changes in sedentary time, ${ }^{8}$ and men retiring from non-manual occupations may even increase their physical activity after retirement. ${ }^{5}$ Unfortunately, the small sample size in the current study, and relatively small proportion of men, did not allow gender and occupational group specific analyses, which might have revealed similar differences.

Our results concerning the opposite levels of workers' physical activity at home and non-home locations between workdays and days off are as expected. However, this difference in physical activity locations by the type of day has not been scientifically examined previously. Importantly, our findings suggest that the location should be considered in future studies examining, for example, associations between physical activity and health outcomes. To the best of our knowledge, this is also the first study to investigate the ageing population's activity behaviour during trips using the type of day. In general, Finnish people frequently walk, cycle or use public transportation, and the sidewalk networks in all Finnish cities are extensive. According to the Finnish National Travel Survey, 30\% of the domestic travel (trips per annum) of Finns were made by walking or cycling and $7 \%$ by public transportation. ${ }^{37}$ Thus, there is no reason to suppose, that in Southwest Finland where our data were collected, or among the age group of our study participants, the situation would be substantially different from elsewhere in Finland. ${ }^{38}$

Perhaps the most interesting finding was that a large proportion of MVPA was achieved during active travel (trip speed $<20 \mathrm{~km} /$ hour) among both workers and retirees. There were also more minutes of MVPA accumulated during active travel on workers' days off than on workdays. Holliday et $a l^{11}$ examined adults' (age 18-85 years) physical activity locations using a GPS and accelerometerbased method, and observed that on average more than $40 \%$ of total physical activity accumulates at home and on roads, and that MVPA often accumulates on roads among older adults. Overall, these results indicate the importance of considering the activity behaviour at different locations and during travel separately for working days and days off among working age populations. In addition, our results highlight the role of active travel in accruing MVPA among older adults. This information can be used when planning future interventions aimed at increasing MVPA among older adults.

There are some limitations to be taken into account when interpreting our cross-sectional findings on the activity behaviour within and between different locations among older adults. First, our study population consisted of older adults, and the results may not be generalisable to younger age groups. In our study population, which represents ageing or retired Finnish public sector workers where the majority of the workers are women $^{39}$; the percentage of men was small among both workers and retirees. Thus, it is unclear how the results vary between genders and this limits the generalisability of the findings for the male population sector, particularly because earlier results, using accelerometer measured data, suggest that older women are more physically active than men. ${ }^{3}$ There was a large sample size difference between workers and retirees, because FIREA and REACT are two separate studies. Nevertheless, the participants of both studies were current or former public sector workers, and mainly differed in terms of their working status. The season in which the measurements were taken may have an effect on the results, particularly in countries with marked seasonal variation in weather conditions, such as in Finland. The seasonal distribution was not entirely similar between the FIREA and REACT studies, thus we adjusted our analysis for the measurement season.

Further, our attempt to indicate active travel using the dichotomy of trips with less or more than $20 \mathrm{~km} /$ hour speed is rudimentary. Our cut-off of $20 \mathrm{~km} /$ hour is for an average travelling speed, and for some individuals, if cycling on average faster than $20 \mathrm{~km} /$ hour, the cycling trip would incorrectly be recorded as passive travel. More developed algorithms would be needed to clarify a travel mode from a GPS-based trip. However, in an urban environment and among the ageing population, travel at a speed of less than $20 \mathrm{~km} /$ hour is also likely to capture cycling. Among adults the average speed of cycling seems to stay between $14^{23}$ and $20 \mathrm{~km} /$ hour. ${ }^{22}$ We did not find prior studies investigating the average speed of cycling among older adults. Additionally, trips with a speed of less than $20 \mathrm{~km} /$ hour may also include slow driving, for example, in traffic congestion; however, long lasting regular traffic congestions are rare in Southwest Finland. The sensitivity analyses conducted by testing different threshold speeds resulted in similar findings.

There are also device-based limitations that should be acknowledged. Raw GPS data may include missing or invalid location information ${ }^{40}$ and the algorithm may detect false trips or miss others. ${ }^{41}$ However, because we logged our GPS points at one-second frequency, and the algorithm detected the locations based on cumulative GPS points, occasional undetected points are unlikely to cause a bias in our results. Nevertheless, false GPS points may have an effect on the calculations of the average speed of the trips as this was calculated based on trip distance and time used. False points will probably increase the distance travelled in a specific time, which may falsely categorise some slower speed trips into the category of higher speed trips. Consequently, the proportion of the trips made with less than $20 \mathrm{~km}$ /hour speed might be underestimated.

Concerning the activity measures, waist-worn accelerometers have a limited ability to detect certain activities, such as cycling, yoga or strength training. ${ }^{10}$ Moreover, water sports cannot be tracked with the device used in our study, thus the total activity was probably underestimated. Furthermore, waist-worn accelerometers cannot separate sitting from standing, thus standing could have been classified as sedentary behaviour. In addition, it has to be noted that on average there was about 1 hour less wear 
time on workers' days off than on workdays. However, the analyses were adjusted for wear time.

Despite its limitations, the study also has many strengths. First, our data were collected with a device including GPS and accelerometer capabilities that allowed us to measure simultaneously both the intensity and the location of physical activity ensuring the synchronisation of the two sensors. Another strength is that we could separate the workdays and days off of workers based on the diary information, instead of estimating workdays based on the day of the week, as has generally been done in prior studies. ${ }^{42}$

In conclusion, by using simultaneous GPS and accelerometer measurements, it was found that workers accrued more MVPA on days off than on workdays. Retirees' physical activity behaviour did not differ between weekdays and weekend days. The locations of workers' activity behaviour also varied between workdays and days off, but a similar difference was not observed in the locations of retirees' activity behaviour between weekdays and weekend days. Importantly, our results showed that a large proportion of the MVPA in this age group accumulated from trips with a speed of less than $20 \mathrm{~km} /$ hour, which suggests that active travel for both commuting and leisure could be a feasible way to increase MVPA among older adults.

\section{Author affiliations}

${ }^{1}$ Department of Public Health, University of Turku, Turku, Finland

${ }^{2}$ Centre for Population Health Research, University of Turku and Turku University Hospital, Turku, Finland

${ }^{3}$ Department of Health Security, Finnish Institute for Health and Welfare, Helsinki, Finland

${ }^{4}$ Population Health Unit, Finnish Institute for Health and Welfare, Helsinki, Finland ${ }^{5}$ Department of Social and Preventive Medicine, École de Santé Publique de I'Université de Montréal (ESPUM), Montreal, Quebec, Canada

${ }^{6}$ University of Montreal Hospital Research Centre (Centre de recherche du Centre Hospitalier de l'Université de Montréal, CRCHUM), Montreal, Quebec, Canada ${ }^{7}$ Department of Movement and Sport Sciences, Ghent University, Gent, Belgium ${ }^{8}$ Clinicum, Faculty of Medicine, University of Helsinki, Helsinki, Finland

Twitter Jaana I Halonen @jaana_halonen

Contributors JIH, JP, JV and SS conceptualised and designed the studies. AP, TL and SP collected the data. JP, SS and SP analysed and visualised the data. YK, BT and RB developed the device for the data collection and the tools for the analysis. SS and TL contributed to the funding of the studies. Each author has participated in the writing, review and editing of the manuscript.

Funding The research projects were supported by Academy of Finland ( 332030 , 286294, 319246, 294154 for SS and 309526 for TL), Ministry of Education and Culture of Finland (to SS) and Juho Vainio Foundation (to TL and SS). The funders were not involved in designing or implementing the studies, or writing the manuscript.

Competing interests YK and BT are co-founders of Mobysens, which developed and markets the SenseDoc V.2.0 device.

Patient consent for publication Not required.

Ethics approval Finnish Retirement and Aging study (FIREA) and enhancing physical activity and healthy ageing among recent retirees-Randomised Controlled In-home Physical Activity Trial (REACT) were conducted in accordance with the Declaration of Helsinki and were approved by the Ethics Committee of the Hospital District of Southwest Finland. Written informed consent was obtained from all the participants in the FIREA and the REACT studies.

Provenance and peer review Not commissioned; externally peer reviewed.

Data availability statement Data are available upon reasonable request. Anonymised partial datasets of the Finnish Retirement and Aging Study and the REACT trial are available by application with bona fide researchers with an established scientific record and bona fide organisations. For more information, please contact Professor Sari Stenholm (sari.stenholm@utu.fi).

Supplemental material This content has been supplied by the author(s). It has not been vetted by BMJ Publishing Group Limited (BMJ) and may not have been peer-reviewed. Any opinions or recommendations discussed are solely those of the author(s) and are not endorsed by BMJ. BMJ disclaims all liability and responsibility arising from any reliance placed on the content. Where the content includes any translated material, BMJ does not warrant the accuracy and reliability of the translations (including but not limited to local regulations, clinical guidelines, terminology, drug names and drug dosages), and is not responsible for any error and/or omissions arising from translation and adaptation or otherwise.

Open access This is an open access article distributed in accordance with the Creative Commons Attribution Non Commercial (CC BY-NC 4.0) license, which permits others to distribute, remix, adapt, build upon this work non-commercially, and license their derivative works on different terms, provided the original work is properly cited, appropriate credit is given, any changes made indicated, and the use is non-commercial. See: http://creativecommons.org/licenses/by-nc/4.0/.

\section{ORCID iDs}

Sanna Pasanen http://orcid.org/0000-0002-7827-2538

Jaana I Halonen http://orcid.org/0000-0003-1142-0388

Ruben Brondeel http://orcid.org/0000-0002-9876-4150

Jussi Vahtera http://orcid.org/0000-0002-6036-061X

Tuija Leskinen http://orcid.org/0000-0001-7499-6128

Sari Stenholm http://orcid.org/0000-0001-7560-0930

\section{REFERENCES}

1 Bangsbo J, Blackwell J, Boraxbekk C-J, et al. Copenhagen consensus statement 2019: physical activity and ageing. Br J Sports Med 2019;53:856-8.

2 Mutikainen S, Helander E, Pietilä J, et al. Objectively measured physical activity in Finnish employees: a cross-sectional study. BMJ Open 2014;4:e005927.

3 Pulakka A, Leskinen T, Koster A, et al. Daily physical activity patterns among aging workers: the Finnish retirement and aging study (FIREA). Occup Environ Med 2019;76:33-9.

4 Audrey S, Procter S, Cooper AR. The contribution of walking to work to adult physical activity levels: a cross sectional study. Int J Behav Nutr Phys Act 2014;11:37-8.

5 Pulakka Aet al. "Physical Activity across Retirement Transition by Occupation and Mode of Commute,". Med. Sci. Sport. Exerc., $p$ 2020;1.

6 Van Domelen DR, Koster A, Caserotti P, et al. Employment and physical activity in the U.S. Am J Prev Med 2011;41:136-45.

7 Barnett I, Van Sluijs E, Ogilvie D. "Changes in household, transport and recreational physical activity and television viewing time across the transition to retirement: longitudinal evidence from the EPICNorfolk cohort,". J Epidemiol Community Heal 2014.

8 Suorsa Ket al. "Objectively Measured Sedentary Time Before and After Transition to Retirement: The Finnish Retirement and Aging Study,". Journals Gerontol. Ser. A 2019.

9 Harvey JA, Chastin SFM, Skelton DA. How sedentary are older people? A systematic review of the amount of sedentary behavior. $J$ Aging Phys Act 2015;23:471-87.

10 Schrack JA, Cooper R, Koster A, et al. Assessing daily physical activity in older adults: unraveling the complexity of monitors, measures, and methods. J Gerontol A Biol Sci Med Sci 2016;71:1039-48.

11 Holliday KM, Howard AG, Emch M, et al. Where are adults active? an examination of physical activity locations using GPs in five us cities. J Urban Health 2017;94:459-69.

12 Hirsch JA, Winters M, Ashe MC, et al. Destinations that older adults experience within their GPs activity spaces relation to objectively measured physical activity. Environ Behav 2016;48:55-77.

13 Brondeel R, Wasfi R, Perchoux C, et al. Is older adults' physical activity during transport compensated during other activities? Comparing 4 study cohorts using GPS and accelerometer data. Journal of Transport \& Health 2019;12:229-36.

14 Jansen M, Ettema D, Pierik F, et al. Sports facilities, Shopping centers or homes: what locations are important for adults' physical activity? A cross-sectional study. Int J Environ Res Public Health 2016;13:287.

15 Ilmarinen JE. "Aging workers," Occupational and Environmental Medicine. BMJ Publishing Group Ltd 2001;58:546-52. 
16 Leskinen T, Pulakka A, Heinonen OJ, et al. Changes in nonoccupational sedentary behaviours across the retirement transition: the Finnish retirement and aging (FIREA) study. J Epidemiol Community Health 2018;72:695-701.

17 Aadland E, Ylvisåker E. Reliability of objectively measured sedentary time and physical activity in adults. PLoS One 2015;10:e0133296.

18 Choi L, Beck C, Liu Z, et al. "Physical Activity: Process Accelerometer Data for Physical Activity Measurement. R package version 0.2-2." 2018

19 Choi L, Liu Z, Matthews CE, et al. Validation of accelerometer wear and nonwear time classification algorithm. Med Sci Sports Exerc 2011;43:357-64.

20 Thierry B. "Linking Finnish SenseDoc data to environmental indicators. Finland pilot project. Version 1.1," 2018.

21 Thierry B, Chaix B, Kestens Y. Detecting activity locations from raw GPs data: a novel kernel-based algorithm. Int $J$ Health Geogr 2013;12:14.

22 Oja P, Vuori I, Paronen O. Daily walking and cycling to work: their utility as health-enhancing physical activity. Patient Educ Couns 1998;33:S87-94.

23 Aittasalo M, Tiilikainen J, Tokola K, et al. Socio-Ecological natural experiment with randomized controlled trial to promote active Commuting to work: process evaluation, behavioral impacts, and changes in the use and quality of walking and cycling paths. Int $J$ Environ Res Public Health 2019;16:1661.

24 Brønd JC, Andersen LB, Arvidsson D. Generating ActiGraph counts from raw acceleration recorded by an alternative monitor. Med Sci Sports Exerc 2017;49:2351-60.

25 Brondeel R, Anaraki JR, KhataeiPour S, et al. "activityCounts: Generate ActiLife Counts. R package version 0.1.2.," 2019.

26 Troiano RP, Berrigan D, Dodd KW, et al. Physical activity in the United States measured by accelerometer. Med Sci Sports Exerc 2008;40:181-8.

27 Chastin SFM, Buck C, Freiberger E, et al. Systematic literature review of determinants of sedentary behaviour in older adults: a DEDIPAC study. Int J Behav Nutr Phys Act 2015;12, :127.

28 King AC, Sallis JF, Frank LD, et al. Aging in neighborhoods differing in walkability and income: associations with physical activity and obesity in older adults. Soc Sci Med 2011;73:1525-33.

29 Sallis JF, Conway TL, Cain KL, et al. Neighborhood built environment and socioeconomic status in relation to physical activity, sedentary behavior, and weight status of adolescents. Prev Med 2018;110:47-54.

30 Sun F, Norman IJ, While AE. Physical activity in older people: a systematic review. BMC Public Health 2013:13:449.

31 Statistics Finland, "Tilastokeskus - Luokitukset - Classification of Occupations 2001 -," 2020. Available: http://www.stat.fi/meta/ luokitukset/ammatti/001-2001/index_en.html [Accessed 2 Jan 2020].

32 Aalto A-M, Aro AR, Teperi J. "RAND-36 terveyteen liittyvän elämänlaadun mittarina. Mittarin luotettavuus ja suomalaiset väestöarvot. " 1999.

33 Aalto A-M, Aro S, Aro AR, et al. "Rand 36-item health survey 1,0 Suomenkielinen versio terveyteen liittyvän elämänlaadun kyselystä : Kyselylomake ja käyttöohjeet," Stakes 1995.

34 Hays RD, Sherbourne CD, Mazel RM. The Rand 36-item health survey 1.0. Health Econ 1993;2:217-27.

35 Halonen JI, Vahtera J, Oksanen T, et al. Socioeconomic characteristics of residential areas and risk of death: is variation in spatial units for analysis a source of heterogeneity in observed associations? BMJ Open 2013;3. doi:10.1136/ bmjopen-2012-002474. [Epub ahead of print: 03 Apr 2013].

36 Kivimäki M, Batty GD, Pentti J, et al. Association between socioeconomic status and the development of mental and physical health conditions in adulthood: a multi-cohort study. The Lancet Public Health 2020;5:e140-9.

37 Traficom, "Finnish National Travel Survey 2016. Available: https:// www.traficom.fi/en/news/publications/finnish-national-travel-survey? toggle=Regional differences in mobility [Accessed 11 Nov 2020].

38 Liikennevirasto. Henkilöliikennetutkimus 2016. Suomalaisten liikkuminen.

39 Statistics Finland, "Women and men in Finland 2016," 2016.

40 Schipperijn J, Kerr J, Duncan S, et al. Dynamic accuracy of GPs receivers for use in health research: a novel method to assess GPs accuracy in real-world settings. Front Public Health 2014:2:21.

41 Kestens $Y$, Thierry B, Chaix B. Re-Creating daily mobility histories for health research from raw GPs tracks: validation of a kernel-based algorithm using real-life data. Health Place 2016;40:29-33.

42 Pulakka A, Stenholm S, Bosma H, et al. Association between employment status and objectively measured physical activity and sedentary Behavior-The Maastricht study. J Occup Environ Med 2018;60:309-15. 